\title{
REVIEW
}

\section{PREDICTIVE VALUE OF THE MORSE FALL SCALE}

\section{Ivana Bóriková, Martina Tomagová, Michaela Miertová, Katarína Žiaková}

Department of Nursing, Jessenius Faculty of Medicine in Martin, Commenius University in Bratislava, Slovakia

Received October 26, 2016; Accepted December 5, 2016. Copyright: This is an open access article distributed under the terms of the Creative Commons Attribution International License (CC BY). http://creativecommons.org/licenses/by/4.0/

\begin{abstract}
Aim: The goal of this study was to analyse relevant research studies focusing on the testing of the predictive value of the Morse Fall Scale measuring device on hospitalized patients. Design: Literature review. Method: Search for full text research studies in Web of Science, Scopus, ScienceDirect, and Summon Discovery Tool (licensed electronic information databases), based on pre-established criteria, and key words, from 1989 to 2016. Results: Sensitivity values ranged from 31\% to 98\%, and specificity values ranged from $8 \%$ to $97 \%$ in 14 analysed studies. The predictive value of the tool in validation studies varies depending on the tested cut-off value, the type of clinical ward, the frequency of assessment, the size and age of the sample, and the length of hospitalisation; therefore, the validity of the results from one study cannot by extrapolated to the entire hospitalized population of patients. Conclusion: The predictive values of the Morse Fall Scale are not stable; they vary in clinical conditions according to various factors. When implementing a tool for a specific clinical ward, an optimum cut-off score must be established to ensure that preventative strategies do not require unnecessary effort on the part of the staff, and do not increase hospital costs.
\end{abstract}

Keywords: falls, hospital, Morse Fall Scale, sensitivity, specificity, review.

\section{Introduction}

In terms of patient safety, falls in hospital are one of the monitored indicators of quality of care. They occur in all age categories, and clinical and diagnostic departments. For patients, they represent potentially serious health consequences, create additional clinical complications, prolong hospitalisation, and increase the costs of care (Nassar, Helou, Madi, 2014; Swartzell et al., 2013; Sung et al., 2014; Tang et al., 2014). Literary sources describe a variety of fall risk factors - internal and external (Virani et al., 2011; Gray-Miceli, Quigley, 2012; Ganz et al., 2013); the identification of individual factors enables the selection of targeted interventions for care plans. An important strategy for in-hospital preventative and monitoring programmes regarding falls is the identification of the fall risk of patients through a measuring tool (Aranda-Gallardo et al., 2013a; Watson et al., 2016), with a view to implementing preventative interventions, so that the costs for patients who do not require them are minimized (Haines et al., 2007).

Corresponding author: Ivana Bóriková, Department of Nursing, Jessenius Faculty of Medicine in Martin, Comenius University in Bratislava, Malá Hora 5, Martin, Slovakia, email: borikova@jfmed.uniba.sk
The precise screening of patients with a high risk of falling is essential for effective nursing care regarding fall prevention. A clinically useful predictive tool should be simple to use, and should have a limited number of items; it should not require specialized assessment, technology or skills, and should be consistent for the target group. Furthermore, it should be based on scientific score testing, with solid inter-rater reliability, and high staff adherence (Oliver, 2008; Oliver, Healey, 2009). The predictive value of the tool includes an analysis of sensitivity, specificity, positive predictive value (PPV), negative predictive value (NPV), and optimal cut-off score selection (Aranda-Gallardo et al., 2013b; McKechnie et al., 2016; Watson, 2016;). Since clinical specializations and patient populations may vary, selecting the proper tool requires careful consideration in order to find the best and most suitable for hospital preventative programmes. While there is no gold standard, the Morse Fall Scale, MFS (Morse et al., 1989a; Morse et al., 1989b) is one of the most tested and recommended tools for the initial assessment of fall risk in clinical practice. In 1989, Janice M. Morse developed and tested the MFS instrument for identifying patients at high risk of physiological falls, comprising approximately $78 \%$ of all falls. The development of the MFS (Morse et al., 1989a) was based on the assessment of a group 
of patients who had suffered falls $(\mathrm{n}=100)$, and a randomized control group of patients who had not suffered a fall $(n=100)$ in a clinical environment of acute (internal medicine and surgical wards) longterm geriatric and rehabilitative care. Based on the testing of physiological and environmental variables, the author identified six significant items for the tool: a history of falling in the past three months, secondary diagnosis, ambulatory aids, intravenous therapy, gait, and mental status. The total MFS ranges from 0-125; low fall risk level is rated at $\leq 20$, medium fall risk level is rated at 25 to 40 , and high fall risk level is rated at $\geq 45$. At the cut-off score of 45 , sensitivity was established at a value of $78 \%$, specificity was established at a value of $83 \%$, PPV was established at a value of $10.3 \%$, NPV was established at a value of $99.2 \%$, and inter-rater reliability was established at a value of $0.96 \%$. The longitudinal MFS evaluation of a group of patients $n$ $=2,689$ (of whom 107 had experienced falls) showed that the tool is a valid predictor of falls - it predicts $82.9 \%$ of physiological falls in the hospital population. Up to $82.9 \%$ of nurses rated the MFS from the perspective of administration as "quick and easy", with a maximum time burden of three minutes, and $63 \%$ of the nurses stated that they would like to have the MFS permanently included in nursing assessments. The score is sensitive to changes in the patient's health state and level of physical disability (Morse et al., 1989b; Morse, 2009).

\section{Aim}

The aim of this review was to find and analyse relevant research studies focusing on testing the predictive value of the MFS measuring tool on hospitalized patients.

\section{Methods}

\section{Design}

Literature review.

\section{Eligibility criteria}

The following selection criteria for studies were chosen on the basis of the research aim. The inclusion criteria were: full-text articles in English published in peer-reviewed journals, focusing on an adult population of inpatients, and including data on the predictive value of the MFS (cut-off score, sensitivity, specificity, positive predictive value, negative predictive value). The exclusion criteria were: studies available only as an abstract, theoretical and policy reviews, conference papers, book publications, those published in languages other than
English, and studies focusing on a paediatric population or non-hospital environments.

\section{Sources}

The relevant data were obtained from the following licensed electronic information databases: Web of Science (Web of Science ${ }^{\mathrm{TM}}$ Core Collection, BIOSIS Citation Index ${ }^{\mathrm{SM}}$, Current Contents Connect, KCI-Korean Journal Database, MEDLINE, SciELO Citation Index), Scopus, ScienceDirect and Summon Discovery Tool.

\section{Search}

The following keywords were used for database searches: "Morse Fall Scale", hospital, sensitivity, and specificity, combined with the Boolean operator AND. Searches focused on the period from 1989, when Morse first published validation studies on development and testing tools (Morse et al., 1989a; Morse et al., 1989b), to the present. The same search criteria were followed with each database.

\section{Study selection and data analyses}

247 potentially relevant documents were found in the aforementioned databases. Duplications $(n=41)$ of individual databases were set aside, and the first classification and analysis of documents $(n=206)$ was made at the level of title, abstract, and key words. Articles lacking the character of a research study, such as protocols; studies lacking relevant data in the abstract; theoretical articles referring to Morse's original studies; various types of literary surveys; national studies without full English text; national cultural-linguistic adaptation studies lacking validity testing; and comparative studies of the MFS and other instruments lacking validity testing $(\mathrm{n}=$ 169) were rejected. The relevant full text documents ( $\mathrm{n}=37$ ) were then subjected to further critical analysis, and 14 studies which complied with all classifying criteria were included in the final survey study. Each study complied with the criteria for clinical research studies, and was further analysed in terms of the patient sample (number of patients, number of falls, age), the values of the tested cut-off score, and MFS predictive values (sensitivity, specificity, positive predictive value, negative predictive value). The documents were searched for, selected, and analysed in September 2016 by two independent reviewers. The selection process is presented in Scheme 1, according to PRISMA recommendations. 


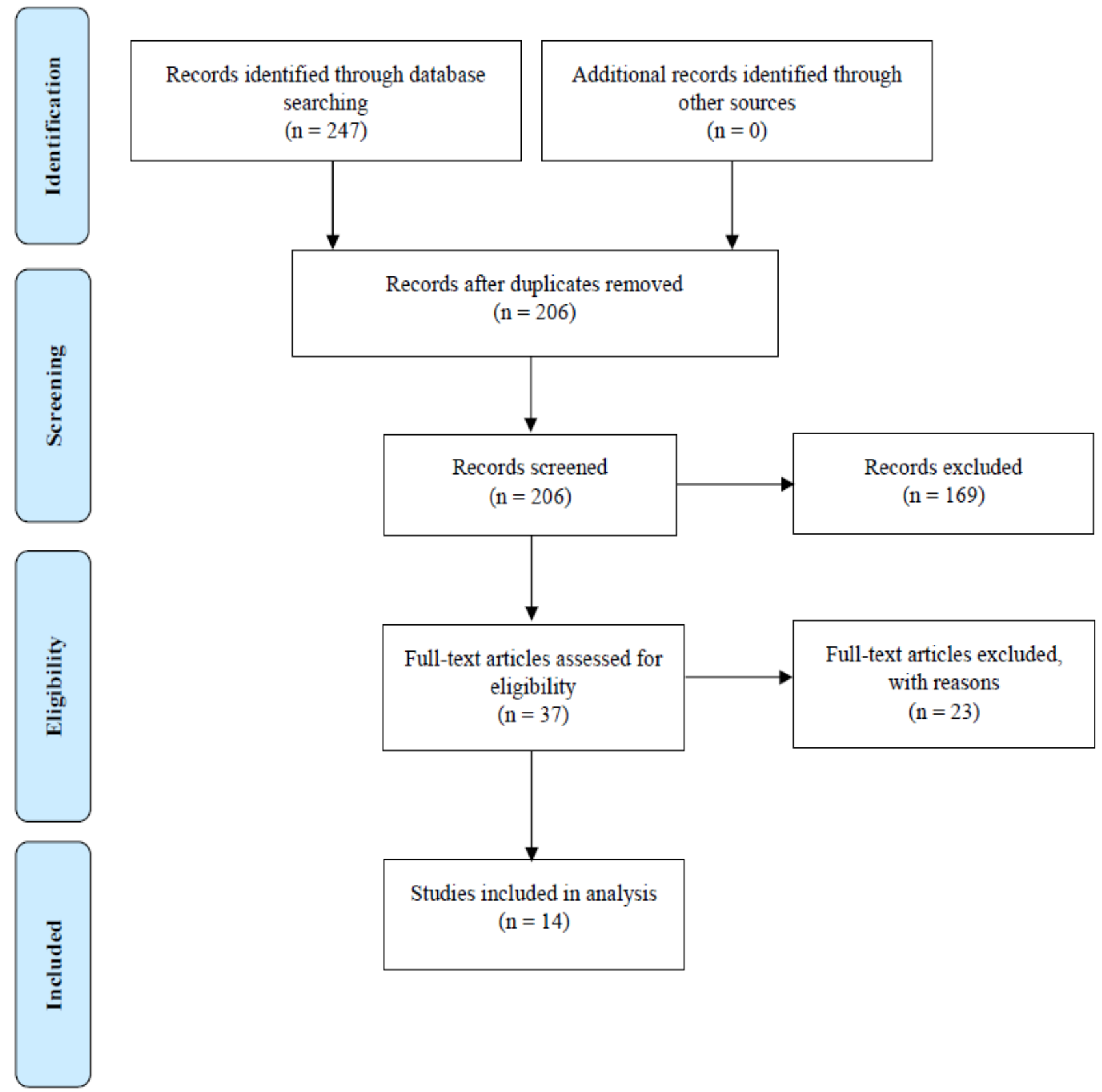

Scheme 1 Steps and results of the screening process - flow diagram

\section{Results}

Table 1 contains the results of the search of the full text studies, which focused on testing for sensitivity and specificity of the MFS. 14 studies published from 1999 to October 2016 complied with the classifying criteria. The predictive value of the MFS was tested by various authors in hospital clinical environments similar to Morse's on a wide spectrum of hospitalized adult patients, including a senior population. The size of the sample varied from 96 (Eagle et al., 1999) to
5,489 respondents (Kim et al., 2007). The values of sensitivity, specificity, PPV and NPV varied depending on the tested numeric value of the MFS cut-off. The lowest sensitivity value was $31 \%$ (Chow et al., 2007), and the highest was $98 \%$ (Watson et al., 2016). The lowest specificity value was $8 \%$ (Watson et al., 2016), and the highest was 97\% (Baek et al., 2014). 
Table 1 Summary of studies - predictive value of the MFS

\begin{tabular}{|c|c|c|c|c|c|c|c|c|}
\hline $\begin{array}{l}\text { Authors of } \\
\text { study, years, } \\
\text { country }\end{array}$ & $\begin{array}{l}\text { Design of } \\
\text { study }\end{array}$ & $\begin{array}{l}\text { Clinical } \\
\text { department }\end{array}$ & $\begin{array}{l}\text { N whole sample } \\
\mathrm{N} / \mathrm{f} \text { sample of those } \\
\text { who fell during the } \\
\text { study }\end{array}$ & Cut-off & $\begin{array}{c}\text { Sensitivity } \\
(\%)\end{array}$ & $\begin{array}{l}\text { Specificity } \\
(\%)\end{array}$ & $\begin{array}{l}\text { PPV } \\
(\%)\end{array}$ & $\begin{array}{l}\text { NPV } \\
(\%)\end{array}$ \\
\hline $\begin{array}{l}\text { Eagle et al., } \\
\text { 1999, Canada }\end{array}$ & $\begin{array}{l}\text { Prospective, } \\
\text { comparative }\end{array}$ & $\begin{array}{l}\text { Rehabilitation, } \\
\text { geriatric }\end{array}$ & $\begin{array}{l}\mathrm{N}=98 \\
\text { Average age } 69 \\
\mathrm{~N} / \mathrm{f}=29\end{array}$ & 45 & 72 & 51 & 38 & 81 \\
\hline $\begin{array}{l}\text { O'Connell, } \\
\text { Myers, 2002, } \\
\text { Australia }\end{array}$ & - & Geriatric & $\begin{array}{l}\mathrm{N}=1,059 \\
\text { Average age } 83.9 \\
\mathrm{~N} / \mathrm{f}=166\end{array}$ & 45 & 83 & 29 & 18 & - \\
\hline $\begin{array}{l}\text { Schwendimann } \\
\text { et al., } 2006 \\
\text { Switzerland }\end{array}$ & $\begin{array}{l}\text { Prospective, } \\
\text { cohort }\end{array}$ & Internal & $\begin{array}{l}\mathrm{N}=386 \\
\text { Average age } 70.3 \\
\mathrm{~N} / \mathrm{f}=47\end{array}$ & $\begin{array}{c}25 \\
45 \\
50 \\
55 \\
*\end{array}$ & $\begin{array}{l}91.5 \\
80.9 \\
80.9 \\
74.5\end{array}$ & $\begin{array}{l}13.9 \\
53.4 \\
58.7 \\
65.8\end{array}$ & $\begin{array}{l}12.8 \\
19.4 \\
21.3 \\
23.2\end{array}$ & $\begin{array}{l}92.2 \\
95.3 \\
95.7 \\
94.9\end{array}$ \\
\hline $\begin{array}{l}\text { Chow et al., } \\
\text { 2007, China }\end{array}$ & Cross-sectional & $\begin{array}{l}\text { Internal, geriatric, } \\
\text { rehabilitation }\end{array}$ & $\begin{array}{l}\mathrm{N}=954 \\
\text { Average age } 70.2 \\
\mathrm{~N} / \mathrm{f}-\end{array}$ & $\begin{array}{l}30 \\
35 \\
40 \\
45\end{array}$ & $\begin{array}{l}42 \\
42 \\
35 \\
31\end{array}$ & $\begin{array}{l}58 \\
58 \\
65 \\
83\end{array}$ & $\begin{array}{l}- \\
- \\
-\end{array}$ & $\begin{array}{l}- \\
- \\
-\end{array}$ \\
\hline $\begin{array}{l}\text { Kim et al., } \\
\text { 2007, Singapur }\end{array}$ & $\begin{array}{l}\text { Prospective, } \\
\text { descriptive }\end{array}$ & $\begin{array}{l}\text { Internal, surgical, } \\
\text { oncology, } \\
\text { orthopedic, } \\
\text { gynecology }\end{array}$ & $\begin{array}{l}\mathrm{N}=5,489 \\
\text { Average age } 55 \\
\mathrm{~N} / \mathrm{f}=60\end{array}$ & $\begin{array}{l}\geq 25 \\
\geq 40 \\
\geq 51\end{array}$ & $\begin{array}{c}88.3 \\
68 \\
55\end{array}$ & $\begin{array}{c}48.3 \\
76 \\
91.2\end{array}$ & $\begin{array}{c}1.9 \\
- \\
6.4\end{array}$ & $\begin{array}{c}99.7 \\
- \\
99.5\end{array}$ \\
\hline $\begin{array}{l}\text { Kim et al., } \\
\text { 2011, Korea }\end{array}$ & $\begin{array}{l}\text { Prospective, } \\
\text { cohort }\end{array}$ & $\begin{array}{l}\text { Internal, surgical, } \\
\text { ICU }\end{array}$ & $\begin{array}{l}\mathrm{N}=356 \\
\text { Average age } 62.6 \\
\mathrm{~N} / \mathrm{f}=71\end{array}$ & $\begin{array}{l}51 \\
50\end{array}$ & $\begin{array}{l}73.2 \\
78.9\end{array}$ & $\begin{array}{l}61.1 \\
55.8\end{array}$ & $\begin{array}{l}31.9 \\
30.8\end{array}$ & $\begin{array}{l}90.2 \\
91.4\end{array}$ \\
\hline $\begin{array}{l}\text { Chapman et al., } \\
\text { 2011, USA }\end{array}$ & $\begin{array}{l}\text { Descriptive, } \\
\text { comparative, } \\
\text { cross-sectional }\end{array}$ & $\begin{array}{l}\text { Internal, surgical, } \\
\text { oncology, } \\
\text { maternity }\end{array}$ & $\begin{array}{l}N=1,540 \\
N / f=57\end{array}$ & $\geq 51$ & 77.2 & 72.8 & 9.9 & 98.8 \\
\hline $\begin{array}{l}\text { Healey, Haines, } \\
\text { 2013, England }\end{array}$ & Pragmatic & $\begin{array}{l}\text { Acute general } \\
\text { hospital }\end{array}$ & $\begin{array}{l}\mathrm{N}=467 \\
\text { Average age } 71.2 \\
\mathrm{~N} / \mathrm{f}=28\end{array}$ & $\begin{array}{l}\geq 55 \\
\geq 25\end{array}$ & $\begin{array}{c}58.6 \\
70\end{array}$ & $\begin{array}{l}80.3 \\
45.7\end{array}$ & $\begin{array}{c}21 \\
10.2\end{array}$ & $\begin{array}{l}95.6 \\
94.3\end{array}$ \\
\hline $\begin{array}{l}\text { Nassar et al., } \\
\text { 2014, Lebanon }\end{array}$ & $\begin{array}{l}\text { Prospective, } \\
\text { observational, } \\
\text { descriptive }\end{array}$ & $\begin{array}{l}\text { Internal, surgical, } \\
\text { oncology, ICU }\end{array}$ & $\begin{array}{l}\mathrm{N}=1,815 \\
\text { Average age } 56.1 \\
\mathrm{~N} / \mathrm{f}=65\end{array}$ & $\begin{array}{l}- \\
> \\
>\end{array}$ & $\begin{array}{c}- \\
36.9 \\
-\end{array}$ & $\begin{array}{c}- \\
- \\
53.9\end{array}$ & $\begin{array}{c}12.4 \\
- \\
-\end{array}$ & $\begin{array}{c}98.2 \\
- \\
-\end{array}$ \\
\hline $\begin{array}{l}\text { Baek et al., } \\
\text { 2014, Korea }\end{array}$ & $\begin{array}{l}\text { Retrospective, } \\
\text { case and } \\
\text { control }\end{array}$ & $\begin{array}{l}\text { Internal, surgical, } \\
\text { others }\end{array}$ & $\begin{array}{l}\mathrm{N}=845 \\
\text { Age range } 18-65 \\
\mathrm{~N} / \mathrm{f}=151\end{array}$ & $\begin{array}{l}\geq 21 \\
\geq 45 \\
\geq 50 \\
\geq 51\end{array}$ & $\begin{array}{l}74 \\
58 \\
44 \\
72\end{array}$ & $\begin{array}{l}77 \\
95 \\
97 \\
91\end{array}$ & $\begin{array}{l}41 \\
73 \\
79 \\
63\end{array}$ & $\begin{array}{l}93 \\
91 \\
89 \\
94\end{array}$ \\
\hline $\begin{array}{l}\text { Sung et al., } \\
\text { 2014, Korea }\end{array}$ & Retrospective & $\begin{array}{l}\text { Internal, surgical, } \\
\text { neurology, } \\
\text { rehabilitation }\end{array}$ & $\begin{array}{l}\mathrm{N}=165 \\
\text { Average age } 55.3 \\
\mathrm{~N} / \mathrm{f}=66\end{array}$ & $\begin{array}{c}25 \\
40 \\
45 \\
50 \\
55 \\
*\end{array}$ & $\begin{array}{c}90.1 \\
69.7 \\
62.1 \\
50 \\
43.9\end{array}$ & $\begin{array}{l}38 \\
64 \\
79 \\
84 \\
87\end{array}$ & $\begin{array}{l}49.2 \\
56.1 \\
66.1 \\
67.3 \\
69.2\end{array}$ & $\begin{array}{c}86.4 \\
76.2 \\
76 \\
71.8 \\
70.2\end{array}$ \\
\hline $\begin{array}{l}\text { Martins da } \\
\text { Costa-Dias et } \\
\text { al., 2014, } \\
\text { Portugal }\end{array}$ & $\begin{array}{l}\text { Case and } \\
\text { control }\end{array}$ & $\begin{array}{l}\text { Internal, surgical, } \\
\text { palliative, long- } \\
\text { term }\end{array}$ & $\begin{array}{l}\mathrm{N}=300 \\
\text { Average age } 76 \\
\mathrm{~N} / \mathrm{f}=100\end{array}$ & $\begin{array}{c}25 \\
45 \\
50 \\
55 \\
*\end{array}$ & $\begin{array}{l}95 \\
78 \\
73 \\
65\end{array}$ & $\begin{array}{l}20 \\
52 \\
56 \\
63\end{array}$ & $\begin{array}{l}37 \\
45 \\
45 \\
46\end{array}$ & $\begin{array}{l}89 \\
82 \\
80 \\
78\end{array}$ \\
\hline $\begin{array}{l}\text { Sung-Hee Yoo } \\
\text { et al., 2015, } \\
\text { Korea }\end{array}$ & Methodological & $\begin{array}{l}\text { Neurology, } \\
\text { neurosurgery, } \\
\text { rehabilitation }\end{array}$ & $\begin{array}{l}\mathrm{N}=1,018 \\
\text { Average age } 56.34 \\
\mathrm{~N} / \mathrm{f}=32\end{array}$ & $\begin{array}{l}40 \\
51\end{array}$ & $\begin{array}{c}78.1 \\
50\end{array}$ & $\begin{array}{l}82.2 \\
90.1\end{array}$ & $\begin{array}{c}12.4 \\
14\end{array}$ & $\begin{array}{l}99.1 \\
98.2\end{array}$ \\
\hline $\begin{array}{l}\text { Watson et al., } \\
\text { 2016, Canada }\end{array}$ & $\begin{array}{l}\text { Cross-sectional, } \\
\text { prospective }\end{array}$ & $\begin{array}{l}\text { Acute general } \\
\text { hospital }\end{array}$ & $\begin{array}{l}\mathrm{N}=500 \\
\text { Age range 18-100 } \\
\mathrm{N} / \mathrm{f}=46\end{array}$ & $\begin{array}{c}25 \\
40 \\
50 \\
55 \\
* \\
\end{array}$ & $\begin{array}{l}98 \\
93 \\
91 \\
87\end{array}$ & $\begin{array}{c}8 \\
19 \\
27 \\
34\end{array}$ & $\begin{array}{l}10 \\
10 \\
11 \\
12\end{array}$ & $\begin{array}{l}97 \\
97 \\
97 \\
96\end{array}$ \\
\hline
\end{tabular}

Cut-off is the limit point on the numerical fall risk scale which defines the patients with a high or low fall risk. Sensitivity - percentage of patients with falls and who were predicted as "high risk" (true positive rate). Specificity - percentage of patients who did not fall and were predicted as "low risk" (true negative rate). Positive predictive value (PPV) - percentage of patients identified as "high risk" who fell. Negative predictive value (NPV) - percentage of patients identified as "low risk" who did not fall. *Sensitivity and specificity were presented in studies even with different cut-off values. - Not reported. 


\section{Discussion}

The necessary resources for fall prevention are limited in terms of staff and funds; therefore, the need to objectify the measuring instrument score for identifying patients at risk of falls is understandable. The predictive qualities of the instrument, crucial for its clinical usefulness (Healey, Haines, 2013), can be validated in studies testing its predictive values. The use of numerical predictive instruments - including the MFS - has its limitations, as some low risk patients fall accidentally, while the majority of high risk patients do not actually fall (Oliver, Healey, 2009), either through lack of opportunity, due to shorter hospital stays, or through effective preventative strategies.

In the analysed studies (Table 1) the authors validated various cut-off score values, frequently using the values of 40 (Kim et al., 2007), 45 (Chow et al., 2007; Sung et al., 2014), 51 (Beak et al., 2013) and 55 (Watson et al., 2016). The cut-off is understood as an acceptable score value to differentiate the normal from the abnormal (Polit, Beck, 2010), and helps to predict the fall risk for each patient; i.e., it distinguishes between low fall risk patients, and high fall risk patients, for whom preventative strategies should be implemented.

When the cut-off value is high, with a high specificity value, the sensitivity value is lower, and the patients at risk may be overlooked. When a lower cut-off produces higher sensitivity values, more patients may be incorrectly deemed to be high fall risk patients (Watson et al., 2016). Morse (2006) suggests a cut-off score of 45 as the lowest for high fall risk, and the best for analysis; however, she notes that it should ideally be calibrated for each ward to facilitate targeted planning of fall prevention strategies. In testing for the best sensitivity and specificity of the MFS in various clinical environments, a cut-off of between 25 , and maximal 55 , is recommended. She emphasizes that in an acute care environment, a value of 25 may be acceptable, as certain wards may have only high fall risk patients, and preventative strategies should protect this group (Morse, 2009). It is difficult to establish a standard for acceptable sensitivity and specificity values for the tool; both values should be as high as possible since establishing a cut-off score may be necessary when considering the costs related to the use of the instrument, allowing for its false positive, or false negative results (Polit, Beck, 2010). Holčík and Komenda (2015) state that a sensitivity of $60 \%$ may be considered adequate. In the analysed studies (Table 1), with various cut-off scores, the sensitivity varies from $31 \%$ to $98 \%$ (Chow et al., 2007; Watson et al., 2016), while specificity varies from $8 \%$ to $97 \%$ (Baek et al., 2014; Watson et al., 2016). Sensitivity and specificity have an inverse relationship: i.e., high sensitivity may be achieved at the expense of low specificity, and vice versa; however, a clinically useful predictive score should combine at least $70 \%$ sensitivity, and 70\% specificity (Baek et al., 2014; Healey, Haines, 2013). Studies with a testing cut-off of 21 (Baek et al., 2014), 40 (Kim et al., 2007; Sung et al., 2014; Sung-Hee Yoo et al., 2015), 45 (Sung et al., 2014), 51 (Chapman et al., 2011; Kim et al., 2011; Baek et al., 2014), and 55 (Schwendimann et al., 2006) come closest to these values. Watson et al. (2016) point to the predictive ability of the MFS to distinguish between high and low fall risk patients. In a cut-off of 25, the sensitivity was high (98\%), but specificity was very low (8\%), which they explain by the fact that some patients who were considered to be high fall risk patients did not actually fall as a result of effective preventative strategies implemented. On the other hand, with such a low cut-off, the majority of patients are evaluated as being at high fall risk, which may lead to the adoption of unnecessary and costly strategies. Therefore, in the hospital in which the study was carried out, the optimum cut-off value for the MFS was set at 55 (sensitivity $87 \%$, specificity 34\%). Similar optimum values for sensitivity and specificity for this cut-off were also calculated by Schwendimann et al. (2006), Healey and Haines (2013), and Martins da Costa-Dias et al. (2014). Healey and Haines (2013) state that a cut-off of $\geq 55$ was statistically significant in the population of the most vulnerable geriatric patients in the age group $\geq 75$ years. However, with sensitivity and specificity values of $<70 \%$ in this sub-group of patients, the use of a cut-off of $\geq 55$ throughout the entire hospital population was problematic. In the study conducted by Sung et al. (2014), in comparison with the age groups with a cut-off of 45 , the sensitivity and specificity for the $<65$ age category was $62 \%$ and $85 \%$, while for the $\geq 65$ age category it was $65 \%$ and $65 \%$. Since the differences between age groups were statistically insignificant, the Korean version of the MFS with a cut-off score of 45 was acknowledged as valid for all age groups.

The PPV and NPV values are dependent on the prevalence of falls in the population of patients, but have no impact on sensitivity and specificity. The best cut-off score will distinguish between the populations and environment, and the selection of the high fall risk definition means a compromise between sensitivity and specificity (Oliver, 2006). If the sensitivity or PPV values are low, the staff will regard the majority of patients in the ward as high fall risk patients, and will consider the use of the 
instrument as unnecessary, leading to poor time management, and poorly targeted interventions. A similar situation is also found in the event of low specificity and NPV values, as a result of which the staff might be falsely assured of the low risk of their patients falling, and, thus, fail to implement interventions (Oliver, 2008; Oliver, Healey, 2009). Low PPV values may be attributed to a low number of high fall risk patients; high NPV values may be due to a large number of patients without falls among a generally large sample of patients with a small number of falls. Therefore, the PPV and NPV values may not be good indicators of the predictive validity of the instrument in a large sample with an extremely low incidence of falls (Kim et al., 2007; Chapman et al., 2011).

When establishing the sensitivity and specificity values of the MFS, the number of patients who have fallen within a certain period of time must be known. For example, in a large sample (Kim et al., 2007), with an average age of 55, and within a time interval of four months, only 60 patients fell. In a smaller sample (Martins da Costa-Dias et al., 2014), with an average age of 76, only 100 patients fell in the course of a year. The differences in the number of patients who fall in the course of the implementation of various studies can be attributed to the size and age of the sample, the type of clinical ward (acute care, long-term care and rehabilitative care), and the implementation of interventions targeted at the prevention and reduction of falls (Schwendimann et al., 2006; Morse, 2009; Sung et al., 2014). The length of time between risk screenings, and when the patient falls, also have an impact on the predictive value of the tool. Watson et al. (2016) state that screening is recommended upon the admission of the patient to the ward if falls are already present in his/her history, although the recording of other risk factors mobility, medication and cognitive deterioration may not be apparent at the time. In addition, the geriatric population may have a higher fall-risk than predicted by the tool, and vice versa, and the health status of the patients with high predicted fall risk may improve, and require less attention than at the first screening. In other words, health status, and fall risk vary throughout hospitalization. The interval between the assessment, and re-evaluation of fall risk varied in the analysed studies: within 24 hours after admission, and after 48 hours (Schwendimann et al., 2006; Kim et al., 2007); from the third day to the fifth day after admission (Eagle et al., 1999); and on the seventh day after admission (Healey, Haines, 2013; Watson et al., 2016). Other studies, such as Nassar et al. (2014), and Chow et al. (2007) did not record this data precisely. Chapman et al. (2011) also consider the frequency of risk assessment as a limitation of their study; while the majority of patients were assessed only once, several patients were assessed more than once (and several patients fell more than once during hospitalization), which contributed to a low PPV value $(9.9 \%)$. Daily recalculation of fall risk may produce more accurate predictive values, but would require additional time. Thus, such frequent assessment in support of targeted interventions would require some justification (Healey, Haines, 2013). Morse draws attention to the frequency of risk assessment in connection with the health status and length of hospitalization ( $\leq 10$ days and $\geq 10$ days) of the patient. In acute care, the patient should be assessed after admission, and at least once per shift in the event of a change in his/her status. In long-term care, it should be once a week (Morse, 2009). The predictive value of this tool varies, depending on a range of factors (tested cut-off value, type of clinical ward, assessment frequency, size and age of the sample, length of hospitalization); therefore, the validity of the results in one study does not necessarily apply to the entire hospital population of patients. Since the main goal of fall risk assessment is to screen patients at risk of accidental falls, and to implement more effective preventative measures, of the four predictive values of the instrument, greater attention should be paid to sensitivity and NPV before its use in clinical practice (Baek et al., 2014). Although the MFS was designed to assess anticipated falls, and does not take into account accidental falls which occur daily in hospital practice, the results of the studies provide significant information for further testing and modification (Chow et al., 2007). However, in order to achieve clinical benefits, the predictive values of the MFS must be tested in a specific clinical environment, with a specific group of patients, i.e., in the actual place where the tool will be used (O'Connell, Myers, 2002; Schwendimann et al., 2006; Chow et al., 2007; Morse, 2009; Spoelstra et al., 2012; Nassar et al., 2014; Sung et al., 2014).

\section{Conclusion}

Based on several validation studies, the MFS is recommended for the identification of high fall risk patients. However, the predictive values of the MFS are not stable; they vary in different clinical conditions due to a number of factors. The prediction of risk by means of a screening tool is not definitive due to the changing multifactorial nature of fall risk during hospitalization. Before implementing a tool for a specific hospital department, the optimal cut-off score should be established to ensure that preventative strategies do not require unnecessary effort from the staff or an increase in hospital costs. 
Despite certain benefits to the prompt screening of fall risk, the administration of a tool is only part of the comprehensive assessment of fall risk factors, and should not replace clinical judgment.

\section{Limitation of the study}

This study only includes material published in English and publicly available on licensed electronic information databases on JFM CU.

\section{Ethical aspects and conflict of interest}

The author declares no conflict of interest. All bibliographic resources used are referenced.

Dedicated to the project of the KEGA 048UK-4/2016 Assessment of risk of falls - for education and practice.

\section{Author contribution}

Conception and design of the literature review (IB), data collection (IB, MT), data analysis and interpretation (IB, MT), manuscript draft (IB, MT), critical revision of the manuscript (MM, KŽ), final approval of the manuscript (IB, MM, KŽ).

\section{References}

Aranda-Gallardo M, Morales-Asencio JM, Canca-Sanchez JC, Barrero-Sojo S, Perez-Jimenez C, Morales-Fernandez A, de Luna-Rodriguez ME, Moya-Suarez AB, Mora-Banderas AM. Instruments for assessing the risk of falls in acute hospitalized patients: a systematic review and meta-analysis. BMC Health Services Research. 2013a;2(13):122.

Aranda-Gallardo M, Morales-Asencio JM, Canca-Sanchez JC, Mora-Banderas AM, Moya-Suarez AB; Group for preventing falls in Hospital Costa del Sol. Instruments for assessing the risk of falls in acute hospitalized patients: a systematic review protocol. Journal of Advanced Nursing. 2013b;69(1):185-193.

Baek S, Piao J, Jin Y, Lee SM. Validity of the Morse Fall Scale implemented in an electronic medical record system. Journal of Clinical Nursing. 2014;23(17-18):2434-2440.

Eagle DJ, Salama S, Whitman D, Evans LA, Ho E, Olde J. Comparison of three instruments in predicting accidental falls in selected inpatients in a general teaching hospital. Journal of Gerontological Nursing. 1999;25(7):40-45.

Ganz DA, Huang Ch, Saliba D, Shier V, Berlowitz D, VanDeusen Lukas C, Pelczarski K, Schoelles K, Wallace LC, Neumann P. Preventing falls in hospitals: a toolkit for improving quality of care. Agency for Healthcare Research and Quality; January 2013 [cited 2016 Oct 12]. Available from:

http://www.ahrq.gov/sites/default/files/publications/files/fallp xtoolkit.pdf

Gray-Miceli D, Quigley PA. Fall prevention: Assessment, Diagnoses, and Intervention Strategies. In: Boltz M, Capezuti E, Fulmer TT, Zwicker D, editors. Evidence-based geriatric Nursing Protocols for Best Practice. 4th ed. New York: Springer Publishing Company; 2012. p. 268-297.
Haines TP, Hill K, Walsh W, Osborne R. Design-related bias in hospital fall risk screening tool predictive accuracy evaluations: systematic review and meta-analysis. The Journals of Gerontology. Series A, Biological Sciences and Medical Sciences. 2007;62(6):664-672.

Healey F, Haines TP. A pragmatic study of the predictive values of the Morse falls score. Age and Ageing. 2013;42(4):462-468.

Holčík J, Komenda M (eds) et al. Matematická biologie: elearningová učebnice. 1. vyd. Brno: Masarykova univerzita; 2015 [cited 2016 Oct 12]. Available from: http://portal.matematickabiologie.cz/ (in Czech)

Chapman J, Bachand D, Hyrkäs K. Testing the sensitivity, specificity and feasibility of four falls risk assessment tools in a clinical setting. Journal of Nursing Management. 2011;19(1):133-142.

Chow SK, Lai CK, Wong TK, Suen LK, Kong SK, Chan CK, Wong IY. Evaluation of the Morse Fall Scale: applicability in Chinese hospital populations. International Journal of Nursing Studies. 2007;44(4):556-565.

Kim EA, Mordiffi SZ, Bee WH, Devi K, Evans D. Evaluation of three fall-risk assessment tools in an acute care setting. Journal of Advanced Nursing. 2007;60(4):427-435.

Kim KS, Kim JA, Choi YK, Kim YJ, Park MH, Kim HY, Song MS. Comparative study on the validity of fall risk assessment acales in Korean hospitals. Asian Nursing Research. 2011;5(1):28-37.

Martins da Costa-Dias MJ, Martins T, Araújo F. Study of the cut-off point of the Morse Fall Scale (MFS). Revista de Enfermagem Referência. 2014;IV(1):63-72.

McKechnie D, Pryor J, Fisher MJ. Predicting falls: considerations for screening tool selection vs. screening tool development. Journal of Advanced Nursing. 2016;72(9):2238-2250.

Morse JM, Morse RM, Tylko SJ. Development of a scale to identify the fall-prone patient. Canadian Journal on Aging. 1989a;8(4):366-377.

Morse JM, Black C, Oberle K, Donahue P. A prospective study to identify the fall-prone patient. Social Science \& Medicine. 1989b;28(1):81-86.

Morse JM. The safety of safety research: the case of patient fall research. Canadian Journal of Nursing Research. 2006;38(2):73-88.

Morse JM. Preventing patient falls. Establishing a fall intervention program. 2th ed. New York: Springer Publishing Company; 2009.

Nassar N, Helou N, Madi C. Predicting falls using two instruments (the Hendrich Fall Risk Model and the Morse Fall Scale) in an acute care setting in Lebanon. Journal of Clinical Nursing. 2014;23(11-12):1620-1629.

O'Connell B, Myers H. The sensitivity and specificity of the Morse Fall Scale in an acute care setting. Journal of Clinical Nursing. 2002;11(1):134-136.

Oliver D. Assessing the risk of falls in hospitals: time for a rethink? Canadian Journal of Nursing Research. 2006;38(2):89-94.

Oliver D. Falls risk-prediction tools for hospital inpatients. Time to put them to bed? Age and Ageing. 2008;37(3):248250.

Oliver D, Healey F. Falls risk prediction tools for hospital inpatients: do they work? Nursing Times. 2009;105(7):18-21. Polit DF, Beck ChT. Essentials of nursing research appraising evidence for nursing practice. 7th ed. 
Philadelphia: Wolters Kluwer Lippincott Williams \& Wilkins; 2010.

Spoelstra SL, Given BA, Given CW. Fall prevention in hospitals: an integrative review. Clinical Nursing Research. 2012;21(1):92-112.

Sung YH, Cho MS, Kwon IG, Jung YY, Song MR, Kim K, Won S. Evaluation of falls by inpatients in an acute care hospital in Korea using the Morse Fall Scale. International Journal of Nursing Practice. 2014;20(5):510-517.

Swartzell KL, Fulton JS, Friesth BM. Relationship between occurrence of falls and fall-risk scores in an acute care setting using the Hendrich II fall risk model. Medsurg Nursing: Official Journal of the Academy of Medical-Surgical Nurses. 2013;22(3):180-187.

Schwendimann R, De Geest S, Milisen K. Evaluation of the Morse Fall Scale in hospitalised patients. Age and Ageing. 2006;35(3):311-313.

Tang WS, Chow YL, Koh SS. The inter-rater reliability test of the modified Morse Fall Scale amongst patients $\geq 55$ years old in an acute care hospital in Singapore. International Journal of Nursing Practice. 2014;20(1):32-38.

Virani T, Schouten JM, McConnell H, Lappan-Gracon S, Santos J, Russell B, Scott C, Burris J, Powell K. Prevention of falls and fall injuries in the older adult. Nursing best practice guideline. Registered Nurses' Association of Ontario, Toronto, Canada; 2011 [cited 2016 Oct 12].

Available from: http://rnao.ca/sites/rnao-

ca/files/Prevention_of_Falls_and_Fall_Injuries_in_the_Older Adult.pdf

Watson BJ, Salmoni AW, Zecevic AA. The use of the Morse Fall Scale in an acute care hospital. Clinical Nursing Studies. 2016;4(2):32-40.

Yoo SH, Kim SR, Shin YS. A prediction model of falls for patients with neurological disorder in acute care hospital. Journal of the Neurological Sciences. 2015;356(1-2):113117. 